\title{
COPYRIGHT EXPLAINER
}

\section{CAN ARTIFICIAL INTELLIGENCE MAKE A COPYRIGHTED WORK?

\author{
Benjamin J. Keele \\ Indiana University Robert H. \\ McKinney School of Law
}

$\mathrm{L}$

ast year, we discussed whether an animal could make a copyrighted work (ALL-SIS Newsletter, Fall 2018, at 5). We imagined our artist Bridget's cat, Napoleon, had placed his painted paws on a print and thereby made a work of art. This time, let us imagine Bridget feeds thousands of images to an autonomous machine learning algorithm (called NAPOLEON), which then produces a novel visual image. Who owns copyright in this image? Bridget? The developer that created NAPOLEON (if Bridget was not also the developer)? Both? Neither?

Starting in the 1980s, scholars have debated whether works by computer programs could be sufficiently original to qualify for copyright. As machine learning has advanced, algorithms have autonomously generated what would be regarded as copyrightable works if they were created by humans. Examples are easy to find. Since U.S. copyright law focuses on economic incentives, let us look at two examples that have demonstrated economic value.

Christie's recently sold a painting for over $\$ 400,000^{2}$ in which an algorithm analyzed thousands of historical portraits and then made its own. Warner Music recently signed a distribution deal with a startup to use an algorithm to generate ambient music for streaming services. The algorithm has created hundreds of tracks with virtually no human involvement. In both of these examples, humans wrote an algorithm and fed it data. After that, the program made the works itself. For the painting and music tracks, no humans made creative decisions that contributed directly to the works.

I think the Naruto case involving the monkey selfie provides an interpretation of the Copyright Act that suggests works autonomously created by artificial intelligence should not qualify for copyright protection. The Naruto court notes that the statute anticipated that authors could sell their copyrights or bequeath them to their heirs. Computer programs, like nonhuman animals, have no heirs and cannot enter into commercial transactions and therefore cannot be authors for copyright purposes. It is true that algorithms have human creators and users, while our friend Naruto was wild. Another possible distinction from Naruto can be found in

1. Timothy L. Butler, Can a Computer Be an Author? Copyright Aspects of Artificial Intelligence, 4 Hastings Comm. \& EnT. L.J. 707 (1982); Pamela Samuelson, Allocating Ownership Rights in Computer-Generated Works, 47 U. PITT. L. REv. 1185 (1985).

2. https://www.vox.com/the-goods/2018/10/29/18038946/art-algorithm

3. https://www.theverge.com/2019/3/27/18283084/warner-music-algorithm-signed-ambient-music-endel

4. Nina I. Brown, Artificial Authors: A Case for Copyright in Computer-Generated Works, 20 Colum. Scr. \& TeCH. L. ReV. 1, 32 (2018). 


\section{COPYRIGHT EXPLAINER \\ 4 cont'd}

cases considering human ownership of copyright in works purportedly created by divine beings. Urantia Foundation $v$. Maaherra ${ }^{5}$ held that humans had been sufficiently involved in compiling divine revelations to justify copyright. So, is artificial intelligence more like a wild animal or a supernatural entity? I am afraid (and a bit relieved) that I do not have the word count to tackle that issue here. Algorithms are likely to continue becoming more independent from human input and more adept at making creative works. That will increase pressure for copyright law to protect and encourage these works. At present, statutory text and precedents do not provide a firm foundation for determining which computer-generated works are protected and who owns them. Given that increasing amounts of money will be at stake, I imagine Congress or the Copyright Office will find a way to grant copyright to works made by artificial intelligence.//

5. 114 F.3d 955 (9th Cir. 1997). 